Association for Information Systems

AIS Electronic Library (AISeL)

Wirtschaftsinformatik 2021 Proceedings

Track 21: Enterprise Modelling and Information

Systems Development

\title{
How the Dimensions of Supply Chain are reflected by Digital Twins: A State-of-the-Art Survey
}

Falk Freese

Kühne Logistics University

André Ludwig

Kühne Logistics University

Follow this and additional works at: https://aisel.aisnet.org/wi2021

Freese, Falk and Ludwig, André, "How the Dimensions of Supply Chain are reflected by Digital Twins: A State-of-the-Art Survey" (2021). Wirtschaftsinformatik 2021 Proceedings. 11.

https://aisel.aisnet.org/wi2021/DEnterpriseModelling21/Track21/11

This material is brought to you by the Wirtschaftsinformatik at AIS Electronic Library (AISeL). It has been accepted for inclusion in Wirtschaftsinformatik 2021 Proceedings by an authorized administrator of AIS Electronic Library (AISeL). For more information, please contact elibrary@aisnet.org. 


\title{
How the Dimensions of Supply Chain are reflected by Digital Twins: A State-of-the-Art Survey
}

\author{
Falk Freese $^{1}$, André Ludwig ${ }^{1}$ \\ ${ }^{1}$ Kuehne Logistics University, Hamburg, Germany \\ \{falk.freese, andre.ludwig\}@ the-klu.org
}

\begin{abstract}
Transparency of supply chains is important. A more transparent supply chain would help to react in real-time by detecting and solving many issues e.g. production interruptions and delivery bottlenecks. A supply chain digital twin can help to increase the transparency and create an overall more robust and flexible supply chain. With real-time data streams from sensors, a digital twin allows simulation, monitoring, and controlling and provides information about its real-world counterpart. Based on a literature review approach, we analyze academic and industrial application and use cases to identify the current state-ofthe-art of supply chain digital twins. Subsequently we develop a classification scheme for supply chain digital twins. The classification scheme provides six different dimensions like scope, actor, asset, flow reference object, performance measurement, and supply chain process that are relevant for digital twins in the context of supply chain.
\end{abstract}

Keywords: Digital Twin, Supply Chain, Literature Review

\section{Introduction}

The Covid-19 global pandemic has shown how vulnerable supply chains are to external events. Industries are alarmed because of fears for their sensitive supply chains. Even a problem at a small supplier can cause issues for global corporations [1]. During the pandemic the supply of face masks became a problem. Within weeks, the Covid-19 global pandemic had turned an item that would otherwise cost just a few cents into one of the most sought-after goods worldwide. Countries around the world suddenly wanted to have many masks at the same time. The prices were climbing to astronomical heights, whether simple surgical masks or high-quality anti-virus masks, like N95 respirators. The same happened to medical ventilators that were needed for treating severe cases of the virus. Many more supply chains for all types of goods were interrupted [2]. A higher level of supply chain transparency and visibility would have helped to detect deviations faster and react on supply shortages in a shorter time frame. Also, predictions on consequences for downstream tiers and proactive countermeasures could be initiated earlier.

Also beyond Covid-19 transparency is needed in supply chains in particular since they have become longer, larger, more dispersed and complex over the past 25 years 
[3]. Transparency provides a way to ensure that the supply chain reduces the risks to supply chain members and end users. These supply chain risks [4] include e.g. risk of community disruptions that impact supplier availability and productivity [3] or the risk of potential non-delivery loses [4]. In addition to reducing risk, transparency also enables members of the supply chain to trace products and to ensure accuracy [5]. An improved transparency and visibility enhance the supply chain performance. They allow high-quality supply chain information exchange resulting in high delivery quality [6]. The need for additional supply chain transparency has been identified and described in detail by numerous authors $[7,8]$. They call for an investigation into how a company should use technology to enable greater visibility and transparency in the supply chain.

One of the most recent developments in providing increased transparency and visibility of products, services and processes is the concept of digital twins [9]. Digital twins have gained a lot of attention for multiple application areas [10]. Technologies like cyber physical systems with a large number of different sensors allow industrial Internet of Things devices connected to the internet to provide a constant stream of contextual data [11]. This data can be processed in real-time based on edge computing, in-memory databases as well as with particular algorithms and simulations [12]. Following Tao et al. [13], a digital twin describes a virtual replication of a product or process. The virtual replication as digital twin allows simulations and provides information about its real-world counterpart [13]. Companies adopt digital twins in order to gain transparency of their products and processes and in the end increase efficiency and effectivity of their business [14].

In this paper we take a look at the state-of-the-art of digital twins and their applications in the field of supply chain. Supply chain is an important application field for digital twins as transparency, prediction and coordination are urgently needed. While a number of companies have already started first implementations of digital twins for supply chains [15-17], the scientific literature of supply chain digital twins is currently scarce. A large amount of papers concerning the digital twin in general can already be found. Some papers focus on the manufacturing and production process of the supply chain [18-20]. However, to the best knowledge of the authors, none of them takes the whole supply chain into account. We address this research gap in our paper. We want to contribute to the understanding of opportunities and challenges of supply chain digital twins to guide future implementation decisions. Therefore, we answer the following research questions:

RQ1: What is the current state-of-the-art of supply chain digital twins?

RQ2: Which dimensions of supply chains should be reflected by digital twins?

RQ3: What are the existing implemented systems for supply chain digital twins?

RQ4: What are their design choices and technical characteristics?

In order to answer these questions, we follow a literature review approach. First, we review the existing scientific literature as well as industry publications about supply chain digital twins to investigate the type of research that has been conducted so far. Then, we analyze the different applications and use cases of supply chain digital twins. Based on the analyzed use cases we develop a classification scheme for supply chain 
digital twins. The classification scheme distinguishes between supply chain and digital twin dimensions. The supply chain dimensions are scope, actor, asset, flow reference object, performance measurement and supply chain process. The digital twin dimensions include purpose, creation time and connection. The classification scheme provides relevant implications for business and research. We contribute to the literature on digital transformation by analyzing the IT artifact of the digital twin. We contribute to research on the digital twin by analyzing the use of the digital twin in the specific context of the supply chain. Our study also contributes to practice by breaking down the relevant dimensions for digital twins in the supply chain.

The paper is structured as follows. First, the theoretical background of digital twins is outlined. Afterwards the methodical approach is described. Subsequently the articles and use cases from industry and academia are analyzed, followed by an outline of relevant dimensions of a classification scheme and a use case analysis. The paper ends with contributions including limitations and an outline for future research.

\section{Theoretical Background}

In the following chapter the theoretical background concerning digital twin is outlined. First, we look at definitions of supply chain and digital twin individually. Then we extract the state-of-the-art of supply chain digital twins from related surveys.

\subsection{Supply Chain}

A supply chain is a complex and dynamic system consisting of suppliers and customers. Companies depend on networks to satisfy customer needs [21, 22]. The company is a building block of this network. In the supply chain, companies are part of complex networks, because satisfying customer needs requires collaboration. The management of the supply chain entails the strategic coordination of traditional business functions and tactical decisions across these business functions. The goal is to improve the longterm performance of individual companies and the supply chain as a whole. In the simplest case the supply chain of a company only takes direct suppliers and direct customers into consideration. With increasing maturity of supply chain management, the scope is expanded up from raw material sourcing to different tiers of production, distribution, up to the final consumer. [23, 24]. The processes of the supply chain are described in the supply chain reference model (SCOR) [25]. It describes on a general level business processes that are performed within a company and between the players in a cross-company value chain. It includes the involved key processes of plan, source, make, deliver, (return) as well as flows of goods, information and payments.

\subsection{Digital Twin}

The idea of digital twins has been around since 1991 [26], but only the Internet of Things concept has promoted its implementation. In the historic context the concept of digital twins was coined first in the aviation industry. A twin is an identical 
manifestation of an object. Digital meaning that its twin is not an object of the real world but data saved in an information system. Glaessgen and Stargel [27] give the following definition: "A Digital Twin is an integrated multiphysics, multiscale, probabilistic simulation of an as-built vehicle or system that uses the best available physical models, sensor updates, fleet history, etc., to mirror the life of its corresponding flying twin." Ivanov et al. [9] define supply chain digital twin as a model that can represent the network state for any given moment in time and allow for complete end-to-end supply chain visibility to improve resilience and test contingency plans. The supply chain of digital twins covers the complete supply chain, from the supplier to production to customer including all intermediaries. The supply chain digital twin tracks all processes according to the SCOR model, as illustrated in Figure 1. The first application was in product lifecycle management where the digital twin supported the product starting from its design phase till its usage phase [28]. The concept of digital twins was then extended for processes, like the manufacturing process [29].

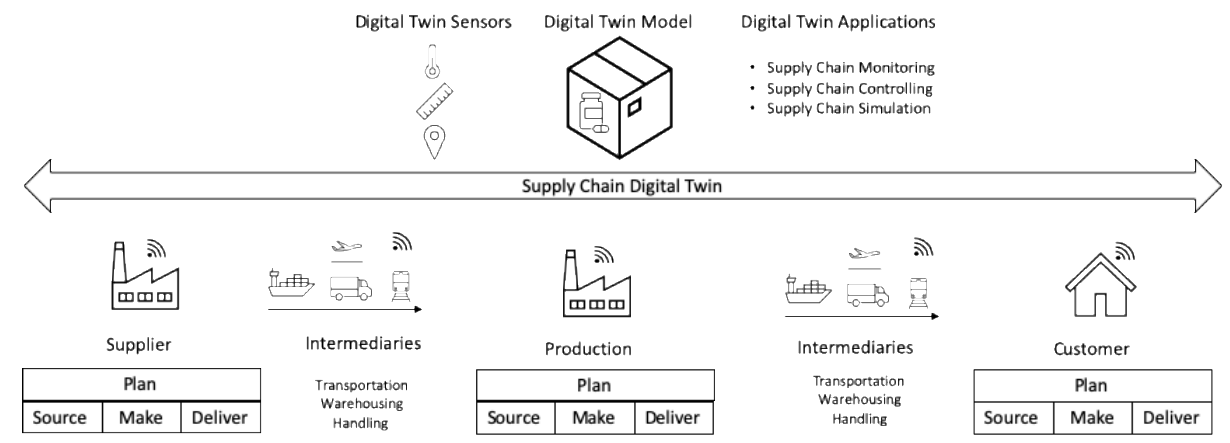

Figure 1. SCOR model and supply chain digital twin

Digital twin technology has the potential of supporting different applications, such as providing real-time transparency (supply chain monitoring). Different technologies are part of a digital twin. A digital twin is using a combination of cyber physical systems, artificial intelligence and machine learning to create a digital copy of a product or process. The sensor data gathered from the physical products or processes, observed and analyzed in digital twins, can be connected and used for predictive maintenance [30]. Tao and Zhang [31] distinguish five aspects of key technologies. One aspect is the interconnection and interaction with the physical system. Multi-agent technologies and standardization technologies fall under this aspect. Another issue is the aspect of smart production and precious services based on the digital twin data. Service encapsulation and artificial intelligence are assigned to that aspect. Modeling, operation and verification form the third aspect of key technologies. The fourth aspect is operation and evolution of digital twins. Key technologies under this aspect are iterative optimization and real-time interaction and convergence. The last aspect is construction and management of digital twin data. All big data technologies fall under this aspect like data cluster storage, data cleaning, data integration and data fusion. 
Digital twins are used in different areas of application from healthcare [32] to construction industry [33]. The area of supply chain for digital twins often focuses on the production part, like shop-floor digital twins [29]. Supply chain digital twins focus on the entire supply chain. They provide real-time data of products and processes in the supply chain and increase the transparency [34].

An example for a digital twin in the context of supply chain is a digital twin of shipments. Finnair Cargo, an air freight carrier, includes the contents of a package or container in its digital twin [35]. If an item is shipped a digital twin has already been created with by preexisting data with e.g. its geometry. Alternatively, the item data can be generated when preparing the shipment, using 3D scanning. The combination of product and packaging data could help companies improve efficiency by automating packaging selection and container packaging strategies to optimize usage and product protection. [35].

\subsection{Related Surveys}

The research that focuses specifically on supply chain digital twins is scare. Srai et al. [34] provide an overview by looking at three industry cases from pharmaceutical, organic food and precision agriculture. They derive possible attributes from those cases consisting of ambitions, scope, boundaries and infrastructure. The attribute scope is further divided in assets, unit ops, network configuration and multi-echelon inventory and service modelling. The attribute infrastructure is divided in platform technology, supply chain mapping tools and digital data acquisition management. In addition, they identify opportunities and challenges for the three industry cases. Opportunities include improved service quality, reliable authentication, digital platforms and resource efficiency. Challenges include end-to-end visibility, sensitivity of information, lack of agreed infrastructure, product-technology complexity and technology accessibility and skills [34]. The authors derive possible attributes of a supply chain digital twins from three industry cases. We include those industry cases in our analysis.

The literature focusing only on the manufacturing part of the supply chain for digital twins provides a larger variety of papers. Those papers focus on specific shop-floor digital twins. Tao and Zhang [31] provide in their paper "Digital Twin Shop-Floor: A New Shop-Floor Paradigm Towards Smart Manufacturing" a new concept for shopfloor digital twins. They identify five key technologies. The first key technology is the interconnection and interaction in the physical shop-floor and the second key technology the modeling, operation and verification of the virtual shop-floor. Another key technology is the construction and management of digital twin data as well as the operation and evolution of the digital twins. The fifth key technology is smart production and precious services based on the digital twin data. Tao and Zhang [31] subsequently identify challenges consisting of keeping adequate two-way connection between physical and virtual spaces. Another challenge is the need for high fidelity models on the digital twin side to provide a stable foundation for the physical object regards to variability, uncertainty and fuzziness. An additional challenge is the seamless integration of the digital twin in respect to the large amount of data [31]. 
Other research focuses on production and cyber physical systems [14, 18, 36]. Uhlemann et al. [37] develop a learning factory-based concept for digital twins demonstrating the potential of real time data acquisition in production systems. Ivanov et al. [9] focus on the ripple effect, resilience, and disruption risks by data-driven optimization, simulation, and visibility in the context of supply chain digital twins. In our paper we address the research gap for supply chain digital twins. Building on aforementioned literature we analyze applications and use cases from industry and academia and develop a classification scheme.

\section{Methodology}

In order to answer the question on the state-of-the-art of supply chain digital twin applications a literature study was conducted in the first quarter of 2020. First, we separated the technical approaches from the conceptual ones and analyzed the various applications and use cases. The results can be found in section 4.1. A further objective of this study was to specify relevant supply chain dimensions and to develop a classification scheme upon existing supply chain digital twin research $[9,34,38]$. Two types of dimensions are relevant in our case, supply chain dimension and digital twin dimensions. They are summarized in section 4.2. and 4.3. Finally, in section 4.4 we assigned use cases to those dimensions and characteristics to identify the focus of the use cases.

We conducted our search in different steps to identify relevant peer-reviewed articles on supply chain digital twins. In the first step we conducted the snow-balling technique on the existing literature reviews on the subject. In the second step we searched in the following databases: Google Scholar, IEEE, ACM, ScienceDirect, Springer. We used combinations of the keywords: digital twin + supply chain. We extended the keywords by synonyms used for digital twins in industry: smart logistics, logistics intelligence. Both terms refer to similar technical concepts as supply chain digital twins and there is a large overlap between the different terms [39, 40]. In addition, we looked at similar concepts such as supply chain control tower and supply chain analytics. In the search for use cases from the industry we looked at university repositories, industry white papers and short technical descriptions on project landing pages. Many industry applications focus on specific digital twins features. We decided to include these articles as we consider that the information provided is a valuable use case.

In total, we obtained approximately 250 papers. To evaluate the search results, we defined inclusion and exclusion criteria for considering a paper or industry use case for our study. These criteria provide a broad foundation to select state-of-the-art papers and use cases. For a paper to be included in our result set, the title and abstract of the paper or the description of the use case must indicate that the work considers the application of digital twin technologies on some type of supply chain. Papers that were nonaccessible or not available as full-paper documents were excluded from the result set. These criteria provide a broad foundation to select state-of-the-art papers and use cases. They comprise:

- Inclusion criteria 1: The paper should be published after 2010. 
- Inclusion criteria 2: From the title and abstract of the paper or the description of the use case, it must be clear that the work considers the application of digital twin technologies on some type of supply chain.

- Exclusion criteria 1: Non-accessible paper or non-available full-paper document.

- Exclusion criteria 2: The length of paper is less than 4 pages.

There are possible limitations to our research methodology. However, we think that our approach has brought together the critical mass of applications and use cases on digital twins in supply chains that exists both in academia and industry, allowing us to carry out an in-depth analysis of the topic.

\section{$4 \quad$ Analysis}

First the applications and use cases are specified. Then the dimensions of supply chain and digital twin are described. Finally, the use cases are analyzed based on the dimensions.

\subsection{Applications and Use Cases from Industry and Academia}

In the following section we analyze the selected articles based on the research questions. We analyze 30 different applications from academia and industry that are outlined in Table 1.

Table 1. Supply Chain Digital Twin Applications and Use Cases

\begin{tabular}{ll}
\hline \multicolumn{1}{c}{ Academia } & \multicolumn{1}{c}{ Authors } \\
\hline Agostinho et al., 2016 [41] & \multicolumn{1}{c}{ Andustry } \\
Arya, 2017 [43] & AnyLogistix, 2020 [44] \\
Glaessgen and Stargel, 2012 [27] & Arm, 2020 [45] \\
Grabis et al., 2020 [46] & Bain \& Company, 2020 [47] \\
Zhu et al., 2017 [48] & BearingPoint, 2020 [49] \\
Ivanov et al., 2019 [9] & Capgemini, 2020 [50] \\
Ivanov and Dolgui, 2020 [51] & DB Schenker, 2020 [52] \\
Kunath and Winkler, 2018 [53] & Deloitte, 2020 [54] \\
Lee et al., 2018 [55] & Deutsche Post DHL Group, 2019 [17] \\
Marmolejo-Saucedo, 2020 [56] & Finnair Cargo, 2020 [35] \\
Moder et al., 2020 [57] & Kuehne + Nagel, 2016 [16] \\
Srai et al., 2019 [34] & LLamasoft, 2019 [58] \\
Trzuskawska-Grzesińska, 2017 [59] & SAP, 2020 [60] \\
Zhuang et al., 2018 [36] & Solvoyo, 2020 [61] \\
Zsifkovits, 2019 [62] & Team GmbH, 2020 [63]
\end{tabular}


The technology of the digital twin can have different development steps and different functionalities. Based on the focus of the application and the use case, different names for digital twin can be found in industry and academia, for example smart logistics or logistics intelligence [16].

\subsection{Supply Chain Dimensions}

Based on the use cases, we identify six supply chain dimensions that are relevant for digital twins to answer RQ2. The dimensions are derived from supply chain literature. We classify the different elements of the supply chain based on different dimensions and corresponding characteristics as outlined in Table 2. Based on the relevant dimensions of supply chain, we analyze the use cases accordingly.

Table 2. Classification Scheme of Supply Chain in Relation to Digital Twins

\begin{tabular}{ll}
\hline \multicolumn{1}{c}{ Dimension } & \multicolumn{1}{c}{ Characteristics } \\
\hline Scope [64] & Internal Supply Chain, External Supply Chain \\
Actor [65] & Shippers, Freight Forwarders, Manufacturers \\
Asset [66] & $\begin{array}{l}\text { Assets at network nodes (i.e. warehouses, plants, } \\
\text { handling equipment), Assets at network links } \\
\text { (i.e. vehicles, trucks, trains, containers) }\end{array}$ \\
Flow Reference Object [67] & $\begin{array}{l}\text { Goods (i.e. stock), Information (i.e. status data, } \\
\text { stock levels), Finances (i.e. credits, invoices), } \\
\text { Liabilities (i.e. bill of lading) }\end{array}$ \\
& $\begin{array}{l}\text { Costs, Quality, Resource Utilization, Flexibility, } \\
\text { Performance Measurement [68] }\end{array}$ \\
& Visibility, Trust, Innovativeness \\
Supply Chain Process [23] & $\begin{array}{l}\text { Demand Planning, Procurement Process, } \\
\text { Production Planning, Production, Warehouse }\end{array}$ \\
\hline
\end{tabular}

Scope: Scope describes the different reach of the digital twin, if the digital twin is just for the internal supply chain of a company or if it is extended to external companies' supply chain. We observed that in most use cases, the focus is on the internal supply chain. With an internal supply chain, the focus is only within one company, therefore interfaces to other companies do not have to be considered. With external supply chains there exists a cross-company digital twin. The data from different companies must be integrated from different information systems. In addition, the companies must share their data with the other companies.

Actor: Actors in the supply chain are decision makers pursuing different objectives. In the analyzed use cases the different actors are not explicitly named. But based on different process steps different actors are involved. Actors include shippers who 
transport goods from one location to another. In addition, there are manufacturers who are responsible for the production of the goods.

Asset: Assets in the supply chain context describe inter alia products and vehicles. The asset dimension of supply chain digital twins refers to any kind of asset. They interact between the various supply chain processes. This dimension also includes other assets such as production plants and machinery. In the investigated use cases a lot of different assets are elaborated in detail with specific digital twin solutions for specific assets. For example, digital twins for ships were used to monitor their location [16].

Flow Reference Object: Flow reference objects describe objects like goods, information and financial values. Flow reference objects move along the process stages of the supply chain. Digital twins consist of physical objects and corresponding information. In the uses cases the flow reference objects goods and information were the main focus. Financial values were not part of the use cases.

Performance Measurement: The dimension of performance measurement describes the criteria to evaluate supply chain performance. The most common performance measurements are cost and quality. Other performance measures are resource utilization, flexibility, visibility, trust and innovativeness [68]. The analyzed use cases focus on cost, quality and visibility. Digital twin applications focus on costreduction targets. Digital twins can accelerate the quality [17]. Another important performance measurement for digital twins is visibility. The digital twin enhances the visibility of a process. Enhanced visibility helps in providing a better basis for decisionmaking and consequently making better short-, mid- and long-term decisions [17, 44].

Supply Chain Process: In the investigated use cases, different cases for specific supply chain processes were identified. There are supply chain digital twins specific for shipment processes or warehouse processes. The production process accounts for a large number of use cases. Supply chain digital twins for processes demand planning or procurement are non-existent.

\subsection{Digital Twin Dimensions}

We combine our findings with the digital twin dimensions of purpose, creation time and connection from Enders and Hoßbach [69] to assign design choices and technical characteristics to the analyzed use cases.

Purpose: The purpose of digital twins can be divided into three main characteristics: simulation, monitoring and control [69].

Simulation is a procedure for the analysis of systems that are too complex for theoretical or formulaic treatment. Real-time analytics analysis the data stream in realtime and allows fast reaction when deviations occur. In the simulation use case, the behavior of physical objects can be reproduced in a virtual space, therefore planning or optimizing products or processes are possible without having to rely on the physical object. Simulation can be used to calculate, when a product reaches an objective [69].

The monitoring use case includes all applications focusing on the representation of the current state and its interpretation of a physical object [69]. This use case describes the visibility aspect of supply chain digital twins and summarizes the different protection applications. 
The control use case describes applications, where supply chain digital twins directly influence products or manufacturing assets [69]. One important and common use case is the traceability of different assets. Track and trace allow to know the exact position of a product in real-time through the flow of the supply chain. If the product deviates from predefined factors, appropriate measures can be taken. In the field of logistics, it can be used to track and trace the transportation of goods. It allows to know when a good will reach a customer. Containers on ships or airfreight on planes as well as items on trucks and trains can be tracked and traced [27]. The tracking of single packages or reusable containers provides a use case $[17,52]$.

Creation Time: Creation time of a digital twin describes if the digital twin was created before or after the corresponding physical object. Digital twins that are created before the physical twin are often used in the development of new products. They are called digital twin prototypes [70]. Digital twins that are created after the physical object are called digital twin instances. In the context of supply chain digital twins in all analyzed use cases the creation time of the digital twin is after the physical twin creation.

Connection: Enders and Hoßbach [69] divide digital twins based on the connection in no connection, one-directional or bi-directional digital twins. This equals the distinction from Kritzinger et al. [19] into digital models, digital shadows and digital twins. The analyzed use cases resemble the findings from Enders and Hoßbach [69]. Most applications that are available use one-directional connection.

\subsection{Digital Twin Use Cases Analysis}

We analyze the different use cases by dimensions to investigate the existing implemented systems for supply chain digital twins and analyze their design choices and technical characteristics. Figure 2 displays the dimensions and its characteristics. It shows the focus of the state-of-the-art use cases. The bubble size represents the number of use cases per characteristic, also given in brackets. 


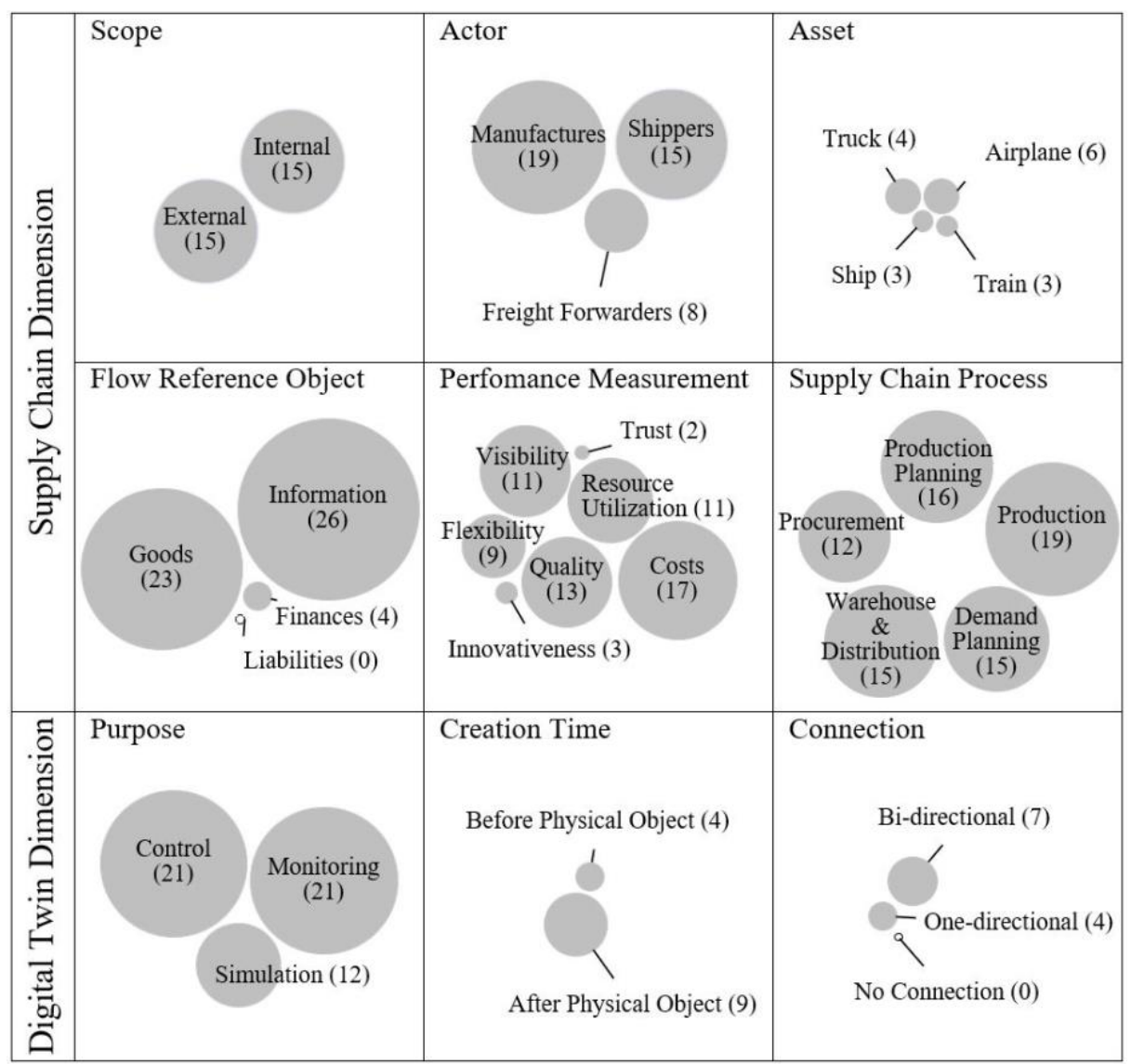

Figure 2. Digital twin use case analysis

The main focus of the use cases are goods and information in the supply chain dimension flow reference object. This confirms that the information provided by sensors is the most important component of digital twins. Since these digital twins relate to specific goods in the supply chain, the connection between information and goods is usually covered in the use cases. Furthermore, this analysis shows that information and goods are the most important factors both in research for academic use cases as well as in industry use cases.

The digital twin dimension purpose with simulation, monitoring and control is mostly addressed in the use cases. An important reason for introducing digital twins in the supply chain context is the monitoring and controlling of processes. Our analysis shows that in addition, simulation remains an important reason, but is of less importance in the supply chain context. For example, containers along the supply chain are often monitored in relation to their GPS position or temperature. Rarely addressed are liabilities and responsibilities as characteristics of the supply chain digital twin. In particular elements of the bill of lading such as confirmation of loading, evidence of 
the terms of contract of carriage and documents of title to goods must be represented by supply chain digital twin as they constitute crucial responsibilities in international trade. They ensure that exporters receive payment and importers receive the goods

So far, in supply chain digital twins, the focus is on information and goods. Financial flows are rarely considered and integrated into the digital twin. With regard to the digital twin dimension connection most use cases utilize bi-directional connections. The connection of digital twins is often not directly addressed in the use cases. On the one hand, sensors deliver data from the object to the digital twin, on the other hand, the digital twin delivers information back to the object. This bi-directional connection was only mentioned in few use cases.

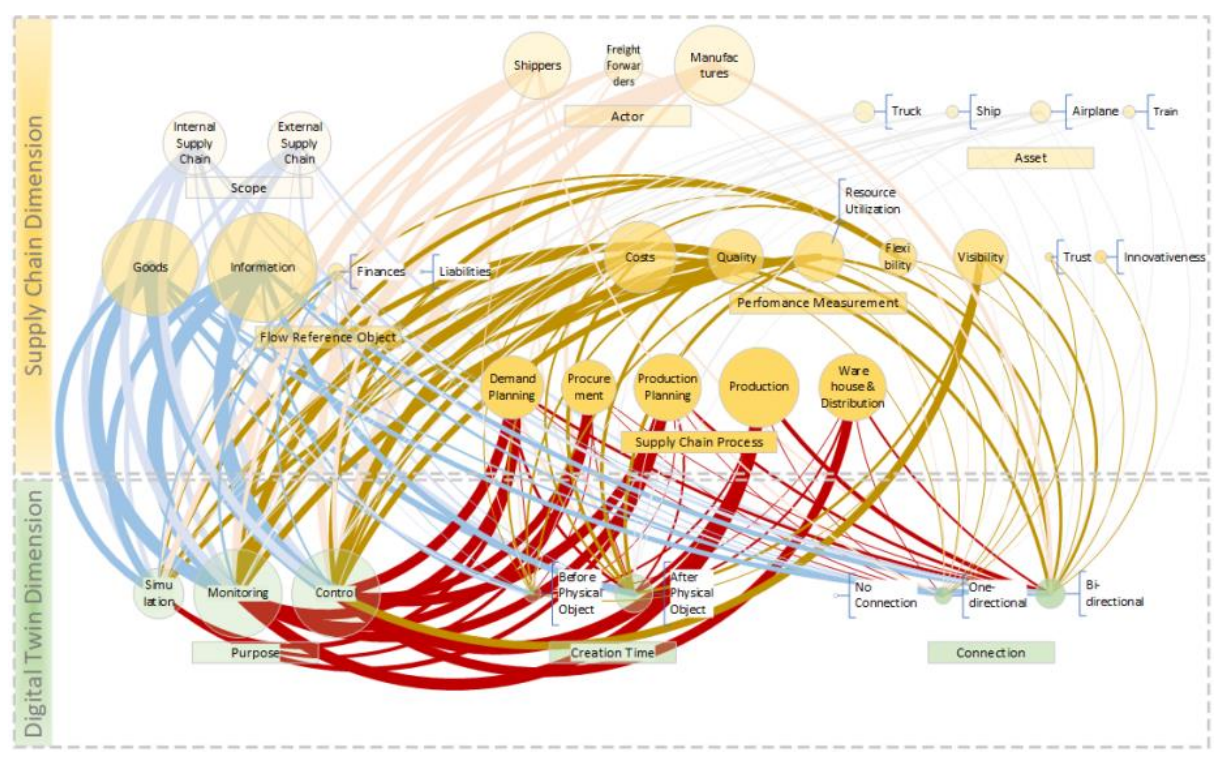

Figure 3. Cross-dimension data map

Figure 3 shows the relationship between the different dimensions using a data map. The bubble size corresponds to the number of use cases. The link shows how often the different dimensions are connected to each other. This can be determined from the thickness of the links. The strongest links are between goods and information and monitoring and controlling. Currently, mainly observational aspects are being addressed with supply chain digital twins. There are hardly any use cases with simulation and planning aspects. The aspect of financial obligations and duties plays an important role in this context and is rarely considered.

Another strong link exists between the digital twin dimension purpose and the supply chain dimension supply chain processes. The individual supply chain processes such as demand planning, procurement, production planning, production and warehouse are often mentioned in connection with monitoring and controlling in the use cases. This shows the importance of the processes in relation to digital twins. The digital twins are integrated within the supply chain processes and provide its purpose. 


\section{Contribution, Limitation, and Future Research}

Based on a systematic literature review, we identified and analyzed different applications and use cases for supply chain digital twins. We analyzed the existing research approaches on the subject of digital twins for supply chains. We developed a classification scheme with the relevant supply chain dimensions to answer the question which elements of the supply chain can be represented by digital twins. We analyzed in detail the existing supply chain digital twins. In addition, we analyzed their design choices and technical characteristics using dimensions of digital twin applications from Enders and Hoßbach [69].

Supply chain digital twins are just in their infancy. Although the concept of digital twins has been around for many years the use of supply chain digital twins is quite new. Only in the last year researchers and practitioners started to cultivate this topic. In our paper we provide an overview of these first approaches and categorize them based on relevant supply chain dimensions. Building on previous supply chain digital twin research $[9,34,38]$ we provide general dimensions for digital twins in the context of supply chain. In addition, we contribute by providing an overview of different supply chain digital twin application and use cases and outline the characteristics that are frequently or rarely used.

This paper has limitations as the literature search was limited to Google Scholar, IEEE, ACM, ScienceDirect and Springer with defined keywords. Even though a vast number of use cases were identified, additional use cases that could not be found with the used search engines and keywords may exist. For example, specific terms which are only used in individual industries, i.e. food tracing in agriculture, may be a reason why use cases were not discovered. Furthermore, use cases may exist that have not yet been published in scientific papers or reported by companies.

Regarding the analysis of the use cases there is a threat of validity in the evaluation of the individual use cases. The assignment of the individual use cases to the dimensions was carried out by two independent domain experts, however there is still the risk of subjective assessments leading into a threat of validity.

The field of supply chain digital twin provides great opportunities for further research. Further research can build on theses dimension and identify and analyze design goals, interoperability and inter-organizational integration issues. We call for future work to deeper investigate the different supply chain digital twin dimension. Especially the underrepresented characteristics need further investigation, e.g. how can the financial aspects be represented in supply chain digital twins.

\section{References}

1. Choi, T.Y., Rogers, D., Vakil, B.: Coronavirus Is a Wake-Up Call for Supply Chain Management, https://hbr.org/2020/03/coronavirus-is-a-wake-up-call-for-supply-chainmanagement, last accessed 2020/04/16.

2. Carter, S.L.: Sold-Out Coronavirus N95 Face Masks Offer Lesson in Price Gouging Bloomberg, https://www.bloomberg.com/opinion/articles/2020-01-31/sold-outcoronavirus-n95-face-masks-offer-lesson-in-price-gouging, last accessed 2020/04/16. 
3. Kashmanian, R.M.: Building Greater Transparency in Supply Chains to Advance Sustainability. Environ. Qual. Manag. 26, 73-104 (2017). https://doi.org/10.1002/tqem.21495.

4. $\mathrm{Wu}, \mathrm{T} .$, Blackhurst, J., Chidambaram, V.: A model for inbound supply risk analysis. Comput. Ind. 57, 350-365 (2006). https://doi.org/10.1016/j.compind.2005.11.001.

5. Zelbst, P.J., Green, K.W., Sower, V.E., Bond, P.L.: The impact of RFID, IIoT, and Blockchain technologies on supply chain transparency. J. Manuf. Technol. Manag. 31, 441457 (2019). https://doi.org/10.1108/JMTM-03-2019-0118.

6. Bartlett, P.A., Julien, D.M., Baines, T.S.: Improving supply chain performance through improved visibility. Int. J. Logist. Manag. 18, 294-313 (2007). https://doi.org/10.1108/09574090710816986.

7. Sodhi, M.M.S., Tang, C.S.: Research Opportunities in Supply Chain Transparency. Prod. Oper. Manag. 28, 2946-2959 (2019). https://doi.org/10.1111/poms.13115.

8. Kache, F., Seuring, S.: Challenges and opportunities of digital information at the intersection of Big Data Analytics and supply chain management. Int. J. Oper. Prod. Manag. 37, 10-36 (2017). https://doi.org/10.1108/IJOPM-02-2015-0078.

9. Ivanov, D., Dolgui, A., Das, A., Sokolov, B.: Digital supply chain twins: Managing the Ripple effect, resilience and disruption risks by data-driven optimization, simulation, and visibility. Springer-Verlag Berlin. 276, 309-332 (2019). https://doi.org/10.1007/978-3-03014302-2.

10. Gartner: Gartner Top 10 Strategic Technology Trends for 2018 - Smarter With Gartner, https://www.gartner.com/smarterwithgartner/gartner-top-10-strategic-technology-trendsfor-2020/, last accessed 2020/02/11.

11. Rajkumar, R., Lee, I., Sha, L., Stankovic, J.: Cyber-physical systems: The next computing revolution. Proc. - Des. Autom. Conf. 731-736 (2010). https://doi.org/10.1145/1837274.1837461.

12. Lasi, H., Fettke, P., Kemper, H.G., Feld, T., Hoffmann, M.: Industry 4.0. Bus. Inf. Syst. Eng. 6, 239-242 (2014). https://doi.org/10.1007/s12599-014-0334-4.

13. Tao, F., Cheng, J., Qi, Q., Zhang, M., Zhang, H., Sui, F.: Digital twin-driven product design, manufacturing and service with big data. Int. J. Adv. Manuf. Technol. 94, 3563-3576 (2018). https://doi.org/10.1007/s00170-017-0233-1.

14. Negri, E., Fumagalli, L., Macchi, M.: A Review of the Roles of Digital Twin in CPS-based Production Systems. Procedia Manuf. 11, 939-948 (2017). https://doi.org/10.1016/j.promfg.2017.07.198.

15. McKinsey: Improving warehouse operations--digitally | McKinsey, https://www.mckinsey.com/business-functions/operations/our-insights/improvingwarehouse-operations-digitally, last accessed 2020/02/26.

16. Kuehne + Nagel: Kuehne + Nagel pioneers new application of logistics market intelligence as part of its digital evolution, https://newsroom.kuehne-nagel.com/kuehne--nagel-pioneersnew-application-of-logistics-market-intelligence-as-part-of-its-digital-evolution/, last accessed 2020/02/26.

17. Deutsche Post DHL Group: Deutsche Post DHL Group | Jun 27, 2019: DHL Trend Report: Implementation of digital twins to significantly improve logistics operations, https://www.dpdhl.com/en/media-relations/press-releases/2019/dhl-trend-reportimplementation-digital-twins-significantly-improve-logistics-operations.html, last accessed 2020/02/26.

18. Uhlemann, T.H.J., Schock, C., Lehmann, C., Freiberger, S., Steinhilper, R.: The Digital Twin: Demonstrating the Potential of Real Time Data Acquisition in Production Systems. Procedia Manuf. 9, 113-120 (2017). https://doi.org/10.1016/j.promfg.2017.04.043. 
19. Kritzinger, W., Karner, M., Traar, G., Henjes, J., Sihn, W.: Digital Twin in manufacturing: A categorical literature review and classification. IFAC-PapersOnLine. 51, 1016-1022 (2018). https://doi.org/10.1016/j.ifacol.2018.08.474.

20. Lim, K.Y.H., Zheng, P., Chen, C.H.: A state-of-the-art survey of Digital Twin: techniques, engineering product lifecycle management and business innovation perspectives. J. Intell. Manuf. 31, 1313-1337 (2020). https://doi.org/10.1007/s10845-019-01512-w.

21. Lummus, R.R., Vokurka, R.J.: Defining supply chain management : a historical perspective and practical guidelines Introduction to supply chain concepts Definition of supply chain. Ind. Manag. Data Syst. Volume 99, 11-17 (1997).

22. Beamon, B.M.: Supply chain design and analysis: Models and methods. Int. J. Prod. Econ. 55, 281-294 (1998). https://doi.org/10.1016/S0925-5273(98)00079-6.

23. Mentzer, J.T., Keebler, J.S., Nix, N.W., Smith, C.D., Zacharia, Z.G.: Defining Supply Chain Management. J. Bus. 22, 1-25 (2001).

24. Janvier-James, A.M.: A New Introduction to Supply Chains and Supply Chain Management: Definitions and Theories Perspective. Int. Bus. Res. 5, 194-208 (2011). https://doi.org/10.5539/ibr.v5n1p194.

25. Huan, S.H., Sheoran, S.K., Wan, G.: A review and analysis of supply chain operations reference (SCOR) model. Supply Chain Manag. 9, 23-29 (2004). https://doi.org/10.1108/13598540410517557.

26. Gelernter, D.H.: Mirror worlds, or, The day software puts the universe in a shoebox-- : how it will happen and what it will mean. Oxford University Press (1991).

27. Glaessgen, E.H., Stargel, D.S.: The digital twin paradigm for future NASA and U.S. Air force vehicles. Collect. Tech. Pap. - AIAA/ASME/ASCE/AHS/ASC Struct. Struct. Dyn. Mater. Conf. 1-14 (2012). https://doi.org/10.2514/6.2012-1818.

28. Grieves, M.W.: Virtually Intelligent Product Systems: Digital and Physical Twins. (2019). https://doi.org/10.2514/5.9781624105654.0175.0200.

29. Qi, Q., Tao, F., Zuo, Y., Zhao, D.: Digital Twin Service towards Smart Manufacturing. Procedia CIRP. 72, 237-242 (2018). https://doi.org/10.1016/j.procir.2018.03.103.

30. Liu, Z., Meyendorf, N., Mrad, N.: The role of data fusion in predictive maintenance using digital twin. AIP Conf. Proc. 1949, (2018). https://doi.org/10.1063/1.5031520.

31. Tao, F., Zhang, M.: Digital Twin Shop-Floor: A New Shop-Floor Paradigm Towards Smart Manufacturing. IEEE Access. 5, 20418-20427 (2017). https://doi.org/10.1109/ACCESS.2017.2756069.

32. Feng, Y., Chen, X., Zhao, J.: Create the Individualized Digital Twin for Noninvasive Precise Pulmonary Healthcare. Significances Bioeng. Biosci. 1, 1-5 (2018). https://doi.org/10.31031/sbb.2018.01.000507.

33. Kaewunruen, S., Rungskunroch, P., Welsh, J.: A digital-twin evaluation of Net Zero Energy Building for existing buildings. Sustain. 11, 1-22 (2018). https://doi.org/10.3390/su11010159.

34. Srai, J.S., Settanni, E., Tsolakis, N., Aulakh, P.K.: Supply Chain Digital Twins: Opportunities and Challenges Beyond the Hype. 26-27 (2019).

35. FInnair Cargo: Data Sharing, https://cargo.finnair.com/en/finnair-cargo-is-helpingspearhead-a-revolutionary-new-data-sharing-standard-called-one-record-1784328, last accessed 2020/08/24.

36. Zhuang, C., Liu, J., Xiong, H.: Digital twin-based smart production management and control framework for the complex product assembly shop-floor. Int. J. Adv. Manuf. Technol. 96, 1149-1163 (2018). https://doi.org/10.1007/s00170-018-1617-6. 
37. Uhlemann, T.H.J., Lehmann, C., Steinhilper, R.: The Digital Twin: Realizing the CyberPhysical Production System for Industry 4.0. Procedia CIRP. 61, 335-340 (2017). https://doi.org/10.1016/j.procir.2016.11.152.

38. Ivanov, D., Dolgui, A.: New disruption risk management perspectives in supply chains: Digital twins, the ripple effect, and resileanness. IFAC-PapersOnLine. 52, 337-342 (2019). https://doi.org/10.1016/j.ifacol.2019.11.138.

39. Uckelmann, D.: A definition approach to smart logistics. Lect. Notes Comput. Sci. (including Subser. Lect. Notes Artif. Intell. Lect. Notes Bioinformatics). 5174 LNCS, 273284 (2008). https://doi.org/10.1007/978-3-540-85500-2_28.

40. Wang, Y., Caron, F., Vanthienen, J., Huang, L., Guo, Y.: Acquiring logistics process intelligence: Methodology and an application for a Chinese bulk port. Expert Syst. Appl. 41, 195-209 (2014). https://doi.org/10.1016/j.eswa.2013.07.021.

41. Agostinho, C., Ducq, Y., Zacharewicz, G., Sarraipa, J., Lampathaki, F., Poler, R., JardimGoncalves, R.: Towards a sustainable interoperability in networked enterprise information systems: Trends of knowledge and model-driven technology. Comput. Ind. 79, 64-76 (2016). https://doi.org/10.1016/j.compind.2015.07.001.

42. Agility Insights: What Is a Supply Chain Control Tower?, https://www.agility.com/insights/smart-shipping/what-is-a-supply-chain-control-tower/, last accessed 2020/08/25.

43. Arya, V., Sharma, P., Singh, A.: An exploratory study on supply chain analytics applied to spare parts supply chain. 24, 1571-1580 (2017). https://doi.org/10.1108/BIJ-04-2016-0053.

44. AnyLogistix: Supply Chain Digital Twins, https://www.anylogistix.com, last accessed 2020/08/02.

45. Logistics - Arm, https://www.arm.com/solutions/logistics, last accessed 2020/08/25.

46. Grabis, J., Stirna, J., Zdravkovic, J.: Capability management in resilient ICT supply chain ecosystems. ICEIS 2020 - Proc. 22nd Int. Conf. Enterp. Inf. Syst. 2, 393-400 (2020). https://doi.org/10.5220/0009573603930400.

47. Bain \& Company: Supply Chain Control Towers: Getting to the Promised Land, https://www.bain.com/insights/supply-chain-control-towers-getting-to-the-promised-land/, last accessed 2020/08/02.

48. Zhu, S., Song, J., Hazen, B.T., Lee, K., Cegielski, C.: How supply chain analytics enables operational supply chain transparency An organizational information processing theory perspective. 48, 47-68 (2017). https://doi.org/10.1108/IJPDLM-11-2017-0341.

49. BearingPoint: Log360 - Der Digital Twin Ihrer Supply Chain| BearingPoint Deutschland, https://www.bearingpoint.com/de-de/unser-erfolg/insights/log360-digital-twin-supplychain/, last accessed 2020/04/23.

50. Capgemini: Global Supply Chain Control Towers Achieving end-to-end Supply Chain Visibility, https://www.capgemini.com/wpcontent/uploads/2017/07/Global_Supply_Chain_Control_Towers.pdf, last accessed 2020/08/25.

51. Ivanov, D., Dolgui, A.: A digital supply chain twin for managing the disruption risks and resilience in the era of Industry 4.0. Prod. Plan. Control. (2020).

52. DB Schenker: Verpackungsberatung und -entwicklung, https://www.dbschenker.com/dede/produkte/verpackungssysteme/verpackungsberatung-und--entwicklung, last accessed 2020/04/02.

53. Kunath, M., Winkler, H.: Integrating the Digital Twin of the manufacturing system into a decision support system for improving the order management process. Procedia CIRP. 72, 225-231 (2018). https://doi.org/10.1016/j.procir.2018.03.192. 
54. Deloitte Deutschland: Supply Chain Control Tower, https://www2.deloitte.com/de/de/pages/operations/articles/supply-chain-controltower.html, last accessed 2020/08/25.

55. Lee, C.K.M., Lv, Y., Ng, K.K.H., Ho, W., Choy, K.L.: Design and application of internet of things-based warehouse management system for smart logistics. Int. J. Prod. Res. 56, $2753-$ 2768 (2018). https://doi.org/10.1080/00207543.2017.1394592.

56. Marmolejo-Saucedo, J.A.: Design and Development of Digital Twins: a Case Study in Supply Chains. Mob. Networks Appl. (2020). https://doi.org/10.1007/s11036-020-01557-9.

57. Moder, P., Ehm, H., Ramzy, N.: Digital Twin for Plan and Make Using Semantic Web Technologies - Extending the JESSI/SEMATECH MIMAC Standard to the Digital Reference. Lect. Notes Electr. Eng. 670 LNEE, 24-32 (2020). https://doi.org/10.1007/9783-030-48602-0_3.

58. LLamasoft: The Digital Supply Chain Twin - An Emerging Trend to Reveal Interconnected Insights, https://llamasoft.com/the-digital-supply-chain-twin-an-emerging-trend-to-revealinterconnected-insights/, last accessed 2020/04/23.

59. Trzuskawska-Grzesińska, A.: Control towers in supply chain management- past and future. J. Econ. Manag. 27, 114-133 (2017). https://doi.org/10.22367/jem.2017.27.07.

60. SAP: Software und Technologie von SAP für digitale Zwillinge, https://www.sap.com/germany/products/digital-supply-chain/digital-twin.html, last accessed 2020/04/23.

61. Solvoyo: Digital Twin is an old idea - just new to supply chain | Supply Chain Analytics, Planning \& Optimization Software, https://www.solvoyo.com/digital-twin-supply-chain/, last accessed 2020/04/23.

62. Zsifkovits, H., Industrielogistik, L., Leoben, M.: Smart Logistics - Technologiekonzepte und Potentiale. 164, 42-45 (2019). https://doi.org/10.1007/s00501-018-0806-9.

63. TEAM GmbH: Logistics Intelligence von TEAM - KPI: Analyse von Daten, KennzahlenGenerierung in der Intralogistik, https://www.team-pb.de/logistics-intelligence/, last accessed 2020/08/25.

64. Barratt, M., Barratt, R.: Exploring internal and external supply chain linkages: Evidence from the field. J. Oper. Manag. 29, 514-528 (2011). https://doi.org/10.1016/j.jom.2010.11.006.

65. Giannoccaro, I., Pontrandolfo, P.: Supply chain coordination by revenue sharing contracts. Int. J. Prod. Econ. 89, 131-139 (2004). https://doi.org/10.1016/S0925-5273(03)00047-1.

66. Mason, S.J., Ribera, P.M., Farris, J.A., Kirk, R.G.: Integrating the warehousing and transportation functions of the supply chain. Transp. Res. Part E Logist. Transp. Rev. 39, 141-159 (2003). https://doi.org/10.1016/S1366-5545(02)00043-1.

67. Pfohl, H.C., Gomm, M.: Supply chain finance: Optimizing financial flows in supply chains. Logist. Res. 1, 149-161 (2009). https://doi.org/10.1007/s12159-009-0020-y.

68. Chan, F.T.S.: Performance measurement in a supply chain. Int. J. Adv. Manuf. Technol. 21, 534-548 (2003). https://doi.org/10.1109/INDIN.2008.4618224.

69. Enders, M.R., Hoßbach, N.: Dimensions of Digital Twin Applications-A Literature Review Dimensions of Digital Twin Applications-A Literature Review Completed Research. Twenty-fifth Am. Conf. Inf. Syst. Cancun. 1-10 (2019).

70. Kahlen, F.J., Flumerfelt, S., Alves, A.: Transdisciplinary perspectives on complex systems: New findings and approaches. (2016). https://doi.org/10.1007/978-3-319-38756-7. 